\title{
Comprometimento Visual com Dano Macular Mínimo numa Lesão Causada por Laser de Femtosegundo
}

\section{Visual Impairment with Minimal Macular Damage in Femtosecond Laser Injury}

José Ferreira Mendes, Cristina Freitas, Rita Gentil ${ }^{1}$

\section{RESUMO}

Descrevemos o caso de um doente do sexo feminino com 26 anos de idade, com história de escotomas centrais bilaterais com 24 horas de evolução, os quais surgiram após a lesão com laser indutor de plasma por produção de nanopartículas. A avaliação oftalmológica incluiu a observação do fundo ocular em midríase, angiografia fluoresceínica e tomografia de coerência ótica.

Numa primeira avaliação, a acuidade visual do olho direito era de 20/20 e do olho esquerdo 20/25. Observavam-se ainda alterações pigmentares foveais na mácula de ambos os olhos. Bilateralmente, a tomografia de coerência ótica revelou uma interrupção central da camada de fotorrecetores; a angiografia fluoresceínica foi normal. Nas avaliações subsequentes, a acuidade visual foi sempre de 20/20 bilateralmente. Os achados anormais observados na tomografia de coerência ótica desapareceram em menos de cinco meses, apesar das queixas subjetivas de escotomas no olho esquerdo se terem mantido.

PALAVRAS-CHAVE: Lasers; Retina/lesões; Tomografia de Coerência Ótica

\section{ABSTRACT}

The authors describe the case of a 26-year-old female patient with a history of bilateral central scotomas which has lasted 24 hours, which appeared after an injury caused by a plasma laser for the production of nanoparticles. The ophthalmologic assessment including observing the ocular fundis in mydriasis, fluorescein angiography and optical coherence tomography (OCT).

In a first assessment, the visual acuity of the right eye was 20/20 and the left eye was 20/25. Foveal pigmentary alterations were observed in the macula of both eyes. Bilaterally, the OCT revealed a central interruption of the photoreceptor layer; the fluorescein angiography was normal. In subsequent assessments, the visual acuity was always 20/20 bilaterally. The abnormal findings observed in the OCT disappeared in less than five months, despite continued subjective complaints of scotomas in the left eye.

KEYWORDS: Lasers; Retina/injuries; Tomography, Optical Coherence 


\section{INTRODUÇÃO}

Os lasers têm diferentes funções e aplicabilidades no dia-a-dia. O seu manuseamento requer precauções no sentido de evitar o atingimento incidental da radiação emitida com estruturas oculares. Um laser pode danificar o tecido ocular por três mecanismos diferentes: térmico, mecânico e fotoquímico. ${ }^{1}$ Em todos os casos, a extensão do dano é determinada pela duração do impulso e pelo nível de energia do feixe. ${ }^{2}$ A energia final do laser é ainda influenciada por outros fatores como a divergência do feixe, a distribuição espacial da energia, a taxa de repetição de impulsos e por fenómenos atmosféricos. ${ }^{3}$

Descrevemos o caso de queimadura retiniana incidental por laser femtosegundo, durante a produção de plasma induzida por nanopartículas. O processo consistia na focagem para o plasma de um laser Titanium-
-Sapphire, com 1 W de impulso de energia de 1 Mj, de comprimento de onda $800 \mathrm{~nm}$, taxa de repetição de impulso de 1 kHz e duração de impulso de 120 fs. De referir ainda que as regras de segurança determinam o uso de óculos de proteção com densidade ótica 8 (fator de atenuação $\left.10^{8}\right)$.

\section{CASO CLÍNICO}

Uma estudante da licenciatura em Física, da Universidade do Minho, sem antecedentes oftalmológicos relevantes, recorreu ao Serviço de Urgência em maio de 2011 com sintomas de escotomas centrais bilaterais, os quais coincidiram vinte e quatro horas após ter observado a produção de plasma induzida nanopartículas secundárias por utilização de laser de femtosegundo. A estudante referiu que utilizou óculos de proteção durante o proce-
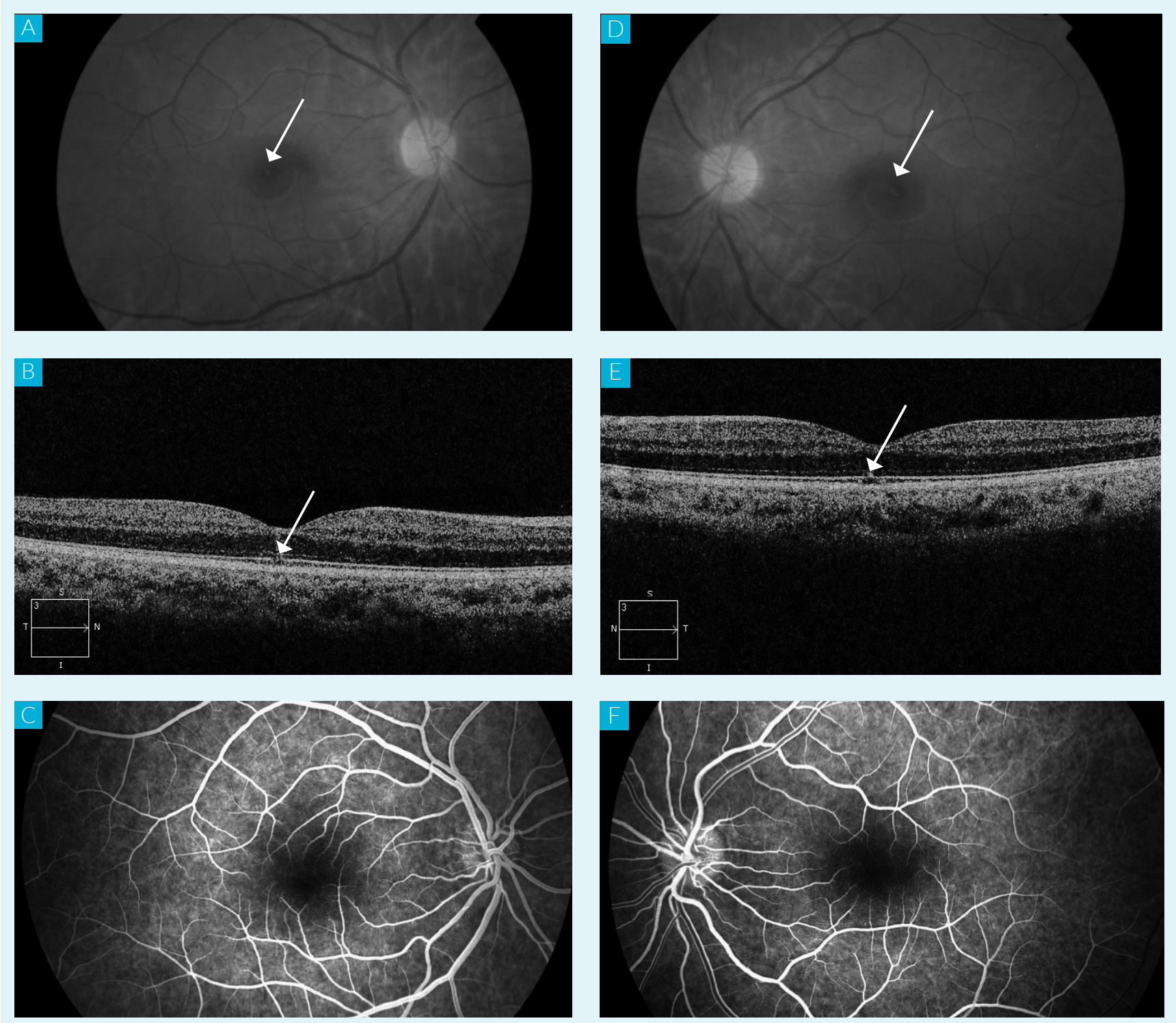

FIGURA 1. Imagens do fundo ocular recolhidas na primeira consulta da doente. Imagens A, B e C relativas ao olho direito e as imagens D, E e F relativas ao olho esquerdo. Fila superior: Retinografia; pequenas lesões esbranquiçadas em ambos os olhos. Fila intermédia: Imagens de OCT vinte e quatro horas após o acidente, com interrupção central da camada de fotorrecetores em ambos os olhos. Fila inferior: Angiografia fluoresceínica, sem alterações. 
dimento. A acuidade visual foi de 20/20 no olho direito e de 20/25 no olho esquerdo. Durante a avaliação da acuidade visual a doente reportou a necessidade de afastar a cabeça e os olhos das letras no sentido de evitar os escotomas. O segmento anterior não apresentava alterações.

A avaliação do polo posterior revelou lesões esbranquiçadas próximo da fóvea, sobretudo no olho esquerdo (Figs. 1-A e 1-D). Foi realizada tomografia de coerência ótica (OCT) (Cirrus HD-OCT, Carl Zeiss Meditec Inc, Dublin, CA), a qual evidenciou uma interrupção discreta
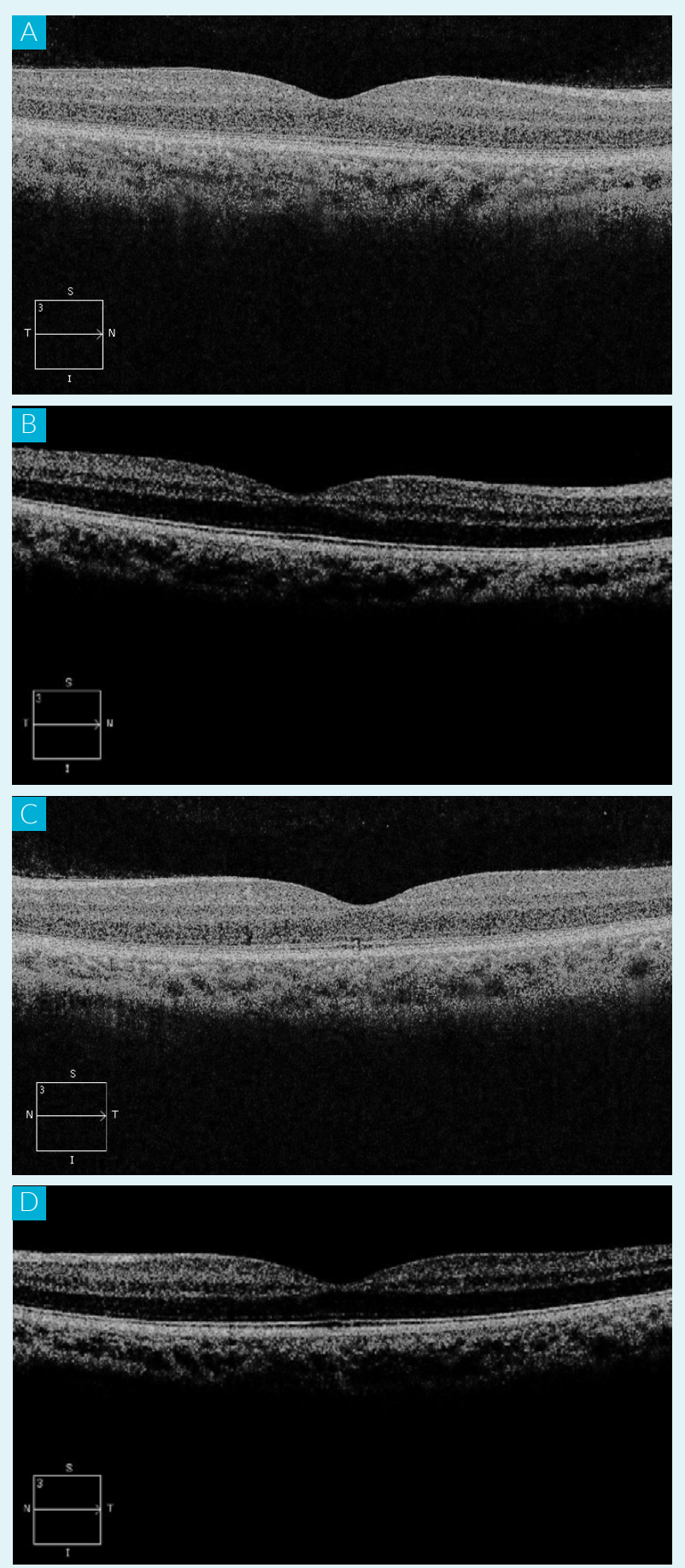

FIGURA 2. Imagens de OCT recolhidas durante o seguimento da doente. Imagens A e B são relativas ao olho direito e C e D relativas ao olho esquerdo. Fila superior: Quatro semanas. Fila inferior: Cinco meses. da camada de fotorrecetores foveolares bilateralmente (Figs. 1-B e 1-E). A angiografia fluoresceínica foi normal em ambos os olhos (Figs. 1-C e 1-F).

Uma perimetria estática automatizada central de dez graus (Humphrey Field Analyzer HFA II-i Series, Carl Zeiss Ophthalmic Systems, Inc., Dublin, CA) foi efetuada, não se identificando a presença de qualquer escotoma (imagens não apresentadas). Na quarta semana de seguimento, a doente mencionou a persistência do escotoma apenas no olho esquerdo. Nessa altura, a acuidade visual era de 20/20 em ambos os olhos; a análise do OCT permitia concluir que se estava perante um processo de normalização das camadas mais externas da retina, já com recuperação total no olho direito (Figs. 2-A e 2-C).

Na consulta do quinto mês, a doente continuou a referir escotoma no olho esquerdo; todavia, as alterações estruturais presentes nos exames de imagem eram mínimas (Figs. 2-B e 2-D).

Ao fim de um ano, a doente manteve as queixas, apesar de a acuidade visual ser de 20/20 e o OCT completamente dentro da normalidade em ambos os olhos (imagens não apresentadas). Como os exames estruturais não eram capazes de explicar as alterações funcionais desta doente, foi realizado mapeamento macular subjetivo com microperimetria (Nidek MP1, Padova, Italy), o qual não identificou variações na sensibilidade da retina (Fig. 3).

\section{DISCUSSÃO}

Este caso demonstra como lesões retinianas podem ocorrer durante a produção de plasma por laser de femtosegundo, mesmo com o uso de óculos de proteção.

Os sintomas parecem ocorrer horas após a exposição da retina à luz ambiente. A ausência de alterações na angiografia fluoresceínica indica que as lesões não foram causadas pela ação direta do laser. ${ }^{5}$ Yang et al descreveu um caso clínico semelhante. ${ }^{6}$ E tal como neste, a lesão parece ter sido causada pela radiação emitida pelo plasma. ${ }^{7}$

Acreditamos que um mecanismo fotoquímico semeIhante a uma queimadura solar possa ter causado a lesão. Como acontece nas queimaduras solares, não se observam alterações na angiografia. ${ }^{8}$ Danos por mecanismos térmicos e mecânicos requerem absorção de grandes quantidades de energia em curtos períodos de tempo, o que não foi o caso. ${ }^{9}$ Ainda, os processos mecânicos causam extensa e visível disrupção dos tecidos periféricos e alterações imediatas na acuidade visual. ${ }^{3}$ Os mecanismos térmicos causam também danos extensos porque o calor irradia do local primário de absorção, provocando danos numa grande área periférica. ${ }^{9}$ Esse não é o nosso caso já que as imagens retinianas do OCT (Figs. 1-B e 1-E) demonstraram uma lesão bem definida e a angiografia excluiu fugas (Figs. 1-C e 

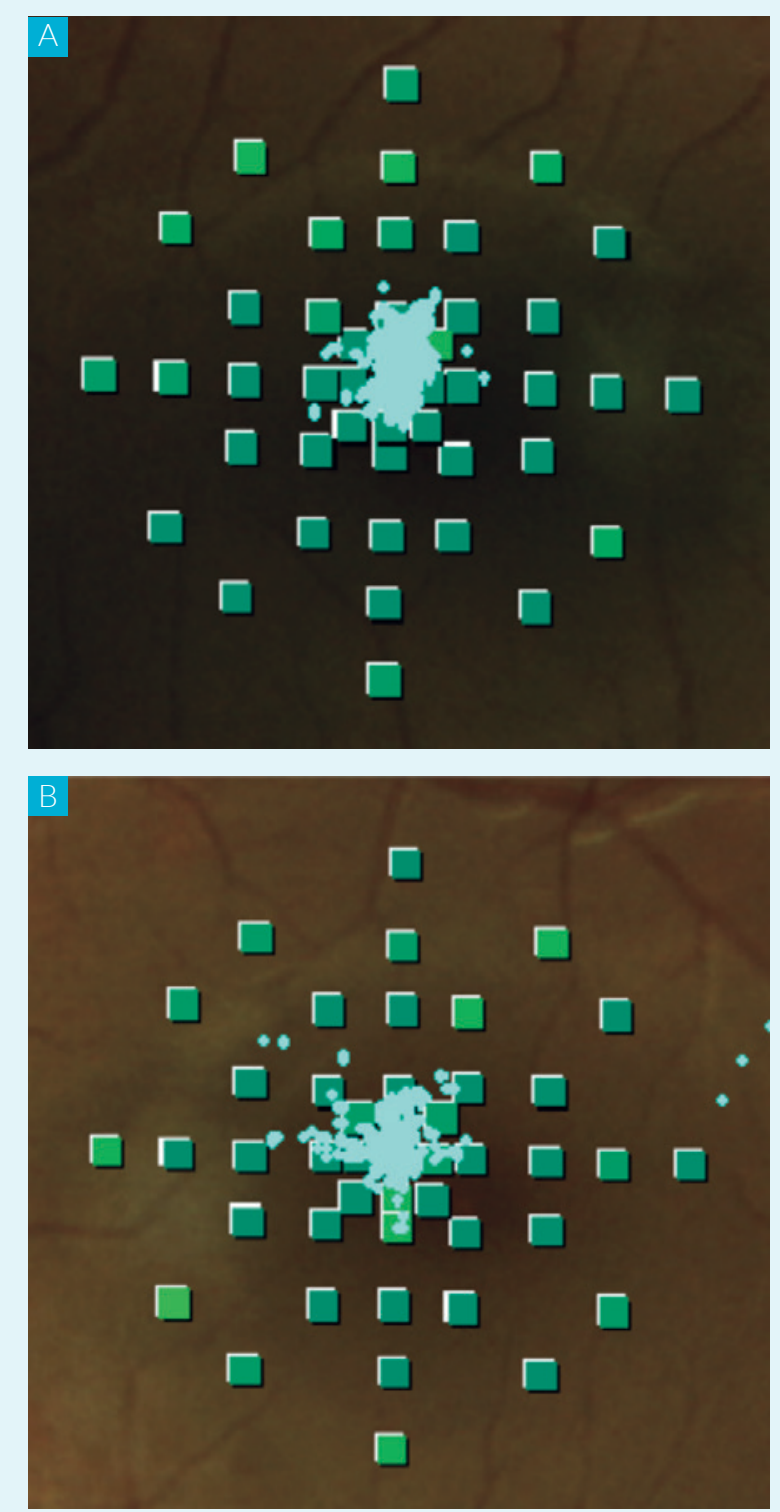

FIGURA 3. Microperimetria do olho direito (A) e esquerdo (B) realizada dez meses após a lesão retiniana. $\bigcirc$ teste consistiu em 45 pontos igualmente separados entre si nos 8 graus centrais, usando o estímulo Goldmann II e uma estratégia 4-2-1.

1-F). Outro achado que nos levou a considerar um mecanismo fotoquímico foi o tempo de aparecimento dos sintomas. Num processo fotoquímico, os sintomas aparecem apenas horas após a exposição, com dano visível das camadas retinianas. Ainda, nestes processos, o dano mantém-se visível nos segmentos exteriores dos fotorrecetores. ${ }^{3}$

Nas lesões fotoquímicas leves, o epitélio pigmentar da retina aparece interrompido e os segmentos exteriores dos fotorrecetores aparecem tortuosos e edemaciados. ${ }^{10}$ As primeiras imagens de OCT (Figs. 1-B e 1-E) revelavam um dano na camada de fotorrecetores que foi desaparecendo progressivamente e que se tornou quase indetetável em menos de cinco meses (Figs. 2-B e 2-D). Os estudos demonstram que fatores como a pigmentação da retina (retinas mais pigmentadas tendem a sofrer maiores danos), o estado de adaptação do olho (olhos adaptados ao escuro são também mais afetados), idade do doente (em estudos animais, os mais novos recuperavam mais rapidamente que os mais velhos) e o ritmo circadiano influenciam a extensão da lesão retiniana causado pela radiação. ${ }^{3} \mathrm{O}$ grau de proteção providenciado pelo uso de óculos também é influenciado por todos os fatores descritos anteriormente.

\section{CONCLUSÃO}

Em suma, descrevemos um caso clínico de uma doente que sofreu lesões retinianas durante a produção de plasma por nanopartículas, apesar do uso de óculos de proteção. A realização deste tipo de experiências implica um maior cuidado e planeamento sobre, por exemplo, como se reduzir o tempo que a retina é diretamente exposta à radiação. Laboratórios onde este tipo de experiências ocorra devem caracterizar melhor a radiação utilizada e adotarem medidas de segurança mais efetivas para prevenção deste tipo de acidentes.

CONFLITOS DE INTERESSE: Os autores declaram a inexistência de conflitos de interesse na realização do presente trabalho.

FONTES DE FINANCIAMENTO: Não existiram fontes externas de financiamento para a realização deste artigo.

CONFIDENCIALIDADE DOS DADOS: Os autores declaram ter seguido os protocolos do seu centro de trabaIho acerca da publicação dos dados de doentes.

\section{REFERÊNCIAS}

1. Barkana Y, Belkin M. Laser eye injuries. Surv Ophthalmol. 2000;44:459-78.

2. Ham WT, Jr, Ruffolo JJ, Mueller HA, Guerry D, 3rd. The nature of retinal radiation damage: dependence on wavelength, power level and exposure time. Vision Res. 1980;20:1105-11.

3. Wu J, Seregard S, Algvere PV. Photochemical damage of the retina. Surv Ophthalmol. 2006;51:461-81.

4. Martinez-Conde S, Macknik SL, Hubel DH. The role of fixational eye movements in visual perception. Nat Rev Neurosci. 2004:5:229-40.

5. Birngruber R, Puliafito CA, Gawande A, Lin WZ, Schoenlein R, Fujimoto J. Femtosecond laser tissue interactions - retinal injury studies. J Quantum Electron. 1987;23:1836-44.

6. Yang X, Jiang F, Song Y, Peng C, Sheng S, Li X. Accidental macular injury from prolonged viewing of a plasma flash produced by a femtosecond laser. Ophthalmology. 2010;117:972-5.

7. Moseley H, Allan D. Intensity of the flash associated with laser-induced plasma in the eye. Phys Med Biol. 1987;32:1159-66.

8. Kung YH, Wu TT, Sheu SJ. Subtle solar retinopathy detected by fourier-domain optical coherence tomography. J Chin Med Assoc. 2010;73:396-8.

9. Marshall J, Mellerio J. Laser irradiation of retinal tissue. $\mathrm{Br}$ Med Bull. 1970;26:156-60.

10. Moriya M, Baker BN, Williams TP. Progression and reversibility of early light-induced alterations in rat retinal rods. Cell Tissue Res. 1986;246:607-21. 